\title{
Batrachochytrium dendrobatidis haplotypes on the hellbender Cryptobranchus alleganiensis are identical to global strains
}

\author{
Atsushi Tominaga ${ }^{1, *}$, Kelly J. Irwin ${ }^{2}$, Michael J. Freake ${ }^{3}$, Kazutaka Suzuki ${ }^{4}$, \\ Koichi Goka ${ }^{4}$ \\ ${ }^{1}$ Department of Natural Sciences, Faculty of Education, University of the Ryukyus, 1 Senbaru, Nishihara, \\ Okinawa 901-0213, Japan \\ ${ }^{2}$ Arkansas Game and Fish Commission, 915 East Sevier Street, Benton, Arkansas 72015, USA \\ ${ }^{3}$ Department of Natural Science and Mathematics, Lee University, 1120 Ocoee St., Cleveland, Tennessee 37311, USA \\ ${ }^{4}$ Invasive Alien Species Research Team, National Institute for Environmental Studies, 16-2 Onogawa, Tsukuba, \\ Ibaraki 305-8506, Japan
}

\begin{abstract}
To determine whether the chytrid fungus Batrachochytrium dendrobatidis $(B d)$ found on the hellbender Cryptobranchus alleganiensis in the southern US is endemic or exotic, we identified the genetic type of this fungus using partial DNA sequences of the internal transcribed spacer (ITS) region. We identified 3 genetic types, which are found on Japanese amphibians other than the Japanese giant salamander Andrias japonicus, a species that belongs to the same family (Cryptobranchidae) as hellbenders. The fungus collected from hellbenders exhibited low genetic diversity and matched the common $B d$ genetic types which have been detected from around the world. These results support that the chytrid fungus on the hellbender is a novel pathogen, as proposed by previous studies. Although we have not observed disease symptoms directly linked to this fungus on this endangered salamander, further evaluation of the influence of this exotic fungus on this species is warranted.
\end{abstract}

KEY WORDS: Cryptobranchidae $\cdot$ Chytridiomycosis $\cdot$ Chytrids $\cdot$ ITS $\cdot$ Novel pathogen hypothesis · North America

Resale or republication not permitted without written consent of the publisher

\section{INTRODUCTION}

The fungus Batrachochytrium dendrobatidis $(B d)$ causes the amphibian disease chytridiomycosis and has been linked to declines in wild frog populations in Australia, New Zealand, North America, South America, and Europe (Berger et al. 1998, Lips 1999 Pessier et al. 1999, Bosch et al. 2001, Bradley et al. 2002, Ron et al. 2003, Weldon et al. 2004, Green \& Dodd 2007, Skerratt et al. 2007). Bd is now widespread throughout many geographic regions and is known to occur all over the world including Asia, where amphibian declines caused by chytridiomycosis have not been reported (Une et al. 2008, Goka et al. 2009, Yang et al. 2009, Savage et al. 2011).

The disease chytridiomycosis was only recently discovered (Berger et al. 1998), and 2 hypotheses have been proposed for the origin of the chytrid fungus (Rachowicz et al. 2005, Pounds et al. 2006, Skerratt et al. 2007, Storfer et al. 2007, Lips et al. 2008, Kilpatrick et al. 2010). The first is the endemic pathogen hypothesis, which posits that $B d$ is endemic to each 
area and population declines result from changes in host susceptibility, pathogen virulence, environmental changes, or a combination of these factors (Morehouse et al. 2003, Weldon et al. 2004, Rachowicz et al. 2005, Morgan et al. 2007, Skerratt et al. 2007, Lips et al. 2008, James et al. 2009). The second, viz. the novel pathogen hypothesis, is that $B d$ was recently introduced to areas where amphibian population declines have been observed (Laurance et al. 1996, Skerratt et al. 2007).

Recently, genetic analyses of $B d$ have been used to attempt to distinguish between the novel and endemic pathogen hypotheses (Morehouse et al. 2003, Morgan et al. 2007, James et al. 2009). These studies revealed that geographically distant isolates appear genetically similar and that relatively little genetic variation exists globally. In addition to these genetic data, several studies indicated sudden appearances of $B d$ in Australia (Aplin \& Kirkpatrick 2000), Central America (Lips et al. 2003, 2006), and North America (Ouellet et al. 2005, Padgett-Flohr \& Hopkins 2009), and $B d$ is regarded as a novel pathogen in these areas.

Weldon et al. (2004) suggested that $B d$ had originated in Africa because chytridiomycosis was found in a Xenopus laevis specimen collected in 1938, and the infection rate of this species was stable without significant differences from the 1930s to 2000s. However, this African origin hypothesis has not been definitive because a source African population with higher genetic diversity has yet to be found (James et al. 2009).

Recently, Goka et al. (2009) conducted a phylogenetic analysis of $B d$ detected in Japanese amphibians, with some samples collected in other countries (USA, Ecuador, and Italy). Using partial DNA sequences of the ITS region, they revealed that the degree of genetic diversity of $B d$ detected in Japan is higher than that in foreign samples. They found 26 haplotypes of $B d$ within the Japanese Islands. Of these, 3 were specific to the Japanese giant salamander Andrias japonicus. These 3 haplotypes formed a monophyletic group and greatly diverged from other haplotypes. Thus, Goka et al. (2009) proposed that the 3 strains ( $\mathrm{B}, \mathrm{J}$, and $\mathrm{K}$ ) of $B d$ on giant salamanders appeared to have established a commensal relationship with this salamander without causing chytridiomycosis and concluded that Japan is one of the origins of the chytrid fungus and that the Japanese giant salamander is a natural host of $B d$. This 'Chytrid out of Asia' hypothesis (Fisher 2009, Goka et al. 2009) has been supported by subsequent studies (Bai et al. 2012).
High infection rates in populations of hellbenders Cryptobranchus alleganiensis have been reported by several researchers (Briggler et al. 2007a, 2008 Gonynor et al. 2011, Souza et al. 2012). The genus Cryptobranchus is a member of the family Cryptobranchidae, which includes only 2 genera (Cryptobranchus and Andrias), and is represented by 2 subspecies C. a. alleganiensis and C. a. bishopi. Both subspecies have experienced severe population declines (Wheeler et al. 2003), and C. a. bishopi has recently been listed as an endangered species under the US Endangered Species Act.

Bodinof et al. (2011) investigated whether $B d$ occurred historically in hellbender populations in Missouri, USA, or whether it was a relatively novel occurrence by examining epidermal tissue from more than 200 archived hellbenders collected from 7 Missouri streams between 1896 and 1994. Their study detected no evidence for endemism of $B d$ in Missouri hellbender populations prior to 1969. However, because genetic strains of $B d$ in the hellbender have not been identified, the origin of $B d$ carried by this species has been unclear.

If $B d$ found on hellbenders is specific to this species and is related to the $B d$ strains carried by the Japanese giant salamander, we could infer a long co-evolutionary relationship between $B d$ and the cryptobranchid salamanders, supporting the endemic hypothesis. But if $B d$ found on hellbenders exhibits low diversity and matches the common type strains distributed globally, we can conclude that $B d$ on hellbenders in North America is a novel invasive species. Thus, identification of the genetic types and diversity of $B d$ carried by hellbenders provides a unique and powerful test to distinguish between the 2 competing hypotheses.

\section{MATERIALS AND METHODS}

\section{Sample collection}

To examine whether $B d$ was present in wild hellbender populations and to identify their haplotypes, field surveys were conducted during August 2009 in Arkansas and Tennessee, USA. Cryptobranchus alleganiensis bishopi were captured by hand by scuba divers in Arkansas, and C. a. alleganiensis were captured by hand by divers snorkeling and lifting rocks in Tennessee. Captured hellbenders were swabbed with a sterile cotton-tipped swab (Men-tip 1P1501, Nihon-Menbo) over the ventral surface of each foot 10 times. We collected 50 samples from 5 rivers 
(Table 1). All swab samples were stored in $200 \mu \mathrm{l}$ of $100 \%$ ethanol at room temperature until required for DNA analysis.

\section{DNA extraction}

Swab samples were first dried at $50^{\circ} \mathrm{C}$ for $2 \mathrm{~h}$ using an aluminum block heater. We then followed the extraction method described by Goka et al. (2001, 2009). Each swab was placed in a microtube containing $200 \mu \mathrm{l}$ of lysis buffer $(1 \mathrm{mg} \mathrm{ml}$ Proteinase $\mathrm{K}$, $0.01 \mathrm{M} \mathrm{NaCl}, 0.1 \mathrm{M}$ EDTA, $0.01 \mathrm{M}$ Tris- $\mathrm{HCl} \mathrm{pH}$ 8.0, and $0.5 \%$ Nonidet P-40). The microtube was then shaken at $15^{\circ} \mathrm{C}$ for 1 min using a vortex mixer. After removing the swab, the tube containing the extract was incubated at $50^{\circ} \mathrm{C}$ for $120 \mathrm{~min}$ and then at $95^{\circ} \mathrm{C}$ for $20 \mathrm{~min}$. After incubation, the extract was diluted to $10 \%$ of its original concentration using TE buffer (0.001 M EDTA, 0.01 M Tris- $\mathrm{HCl} \mathrm{pH}$ 8.0) and used as the source of DNA template for PCR assay.

\section{Nested PCR assay}

A nested PCR assay followed Goka et al. (2009). We amplified the target DNA using Bd18SF1 (5'TTT GTA CAC ACC GCC CGT CGC-3') and Bd28SR1 (5'-ATA TGC TTA AGT TCA GCG GG-3') designed by Goka et al. (2009) for the first PCR step. We then amplified the first-round PCR products using Bd1a (5'-CAG TGT GCC ATA TGT CAC G$\left.3^{\prime}\right)$ and Bd2a (5'-CAT GGT TCA TAT CTG TCC AG-3') designed by Annis et al. (2004) in the second amplification step. Polymerase chain reaction assays were conducted, as described in Goka et al. (2001), with $2 \mu \mathrm{l}$ of each template DNA in a total reaction volume of $50 \mu \mathrm{l}$. The PCR reaction mix contained $0.2 \mathrm{mM}$ of each dNTP, $2 \mathrm{mM} \mathrm{MgCl}, 1.25$ units of Taq DNA polymerase (Amplitaq Gold), and $0.5 \mathrm{mM}$ of each primer. All PCR reagents were purchased from PerkinElmer Applied Biosystems. The conditions for the first amplification were an initial denaturation for $9 \mathrm{~min}$ at $95^{\circ} \mathrm{C} ; 30$ cycles of $30 \mathrm{~s}$ at $94^{\circ} \mathrm{C}$, $30 \mathrm{~s}$ at $50^{\circ} \mathrm{C}$, and $2 \mathrm{~min}$ at $72^{\circ} \mathrm{C}$; and a final extension for $7 \mathrm{~min}$ at $72^{\circ} \mathrm{C}$. The conditions for the second amplification were an initial denaturation for $9 \mathrm{~min}$ at $95^{\circ} \mathrm{C} ; 30$ cycles of $30 \mathrm{~s}$ at $94^{\circ} \mathrm{C}, 30 \mathrm{~s}$ at $65^{\circ} \mathrm{C}$, and $30 \mathrm{~s}$ at $72^{\circ} \mathrm{C}$; and a final extension for $7 \mathrm{~min}$ at $72^{\circ} \mathrm{C}$. Each sample was tested twice. For each amplification, we included a positive control using DNA extracted from a swab taken from an Argentine horned frog Ceratophrys ornata (Une et al. 2008) and a negative control using TE buffer without any DNA. PCR products were separated on $6 \%$ polyacrylamide gels, and bands of DNA fragments were made visible by means of ethidium bromide staining under UV light. Each product of the second amplification was subcloned into a vector plasmid by using a pT7 Blue Perfectly Blunt Cloning Kit (Novagen, EMD Bioscience) and transformed into Escherichia coli in accordance with the manufacturer's protocol. The cloned fragments in 3 positive clones for each nested PCR product were sequenced using T7 promoter and U19 reverse primers on an ABI3730 Sequencer (Applied Biosystems). Using haplotype sequences from Goka et al. (2009), we identified haplotypes of $B d$ carried by hellbenders.

\section{RESULTS}

Of the 50 hellbender swab samples, 18 samples $(36 \%)$ were identified as $B d$ positive (Table 1). Positive $B d$ samples were detected in all 5 rivers. Prevalence varied from 16 to $50 \%$. The highest rate was observed in the Hiwassee River and the lowest in Tumbling Creek (Table 1).

Of 18 positive samples, 14 were identified as haplotype A of Goka et al. (2009) (AB435211), 2 were hap-

Table 1. Host species, sample collection sites, number of total samples, number of Batrachochytrium dendrobatidis-positive samples, and \% prevalence with $95 \%$ confidence intervals in this study

\begin{tabular}{|llccc|}
\hline Host species & Locality & N samples & $\begin{array}{c}\text { N positive } \\
\text { Prevalence } \\
(95 \% \text { CI) }\end{array}$ \\
\hline Cryptobranchus alleganiensis bishopi & & Eleven Point River, Arkansas, USA & 9 & 2 \\
C. a. alleganiensis & Hiwassee, Tennessee, USA & 16 & $22(2.8-60.0)$ \\
C. a. alleganiensis & Tumbling Creek, Tennessee, USA & 6 & $50(24.6-75.3)$ \\
C. a. alleganiensis & Little River, Tennessee, USA & 9 & 1 & $16(0.4-64.1)$ \\
C. a. alleganiensis & Beaverdam Creek, Tennessee, USA & 10 & 3 & $33.3(7.4-70.0)$ \\
Total & & 50 & $40(12.1-73.8)$ \\
\end{tabular}


Table 2. Cryptobranchus alleganiensis. Sample numbers, collection locality, sampling method, and haplotype of Batrachochytrium dendrobatidis-positive samples. Eleven Point River is located in Arkansas; all other sites are in Tennessee. The 2 samples from Arkansas were C. a. bishopi, whereas all samples from Tennessee were $C$. a. alleganiensis

\begin{tabular}{|clc|}
\hline $\begin{array}{c}\text { Sample } \\
\text { number }\end{array}$ & Locality & Haplotype \\
\hline AK10 & EP07, Eleven Point River & A \\
AK11 & EP18, Eleven Point River & A \\
TN01 & Hiwassee & A \\
TN06 & Hiwassee & A \\
TN07 & Hiwassee & L \\
TN09 & Hiwassee & A \\
TN11 & Hiwassee & E \\
TN13 & Hiwassee & L \\
TN14 & Hiwassee & A \\
TN19 & Hiwassee & A \\
TN25 & Tumbling Creek & A \\
TN32 & Little River & A \\
TN33 & Little River & A \\
TN35 & Little River & E \\
TN36 & Beaverdam Creek & A \\
TN37 & Beaverdam Creek & A \\
TN43 & Beaverdam Creek & A \\
TN44 & Beaverdam Creek & A \\
\hline
\end{tabular}

lotype E of Goka et al. (2009) (AB435214), and 2 were haplotype L of Goka et al. (2009) (AB435221) (Table 2). From 3 rivers (Eleven Point River of Arkansas, Tumbling Creek and Beaverdam Creek of Tennessee), only single strains (haplotype A) were detected, whereas multiple strains (haplotypes A, E, and $\mathrm{L}$ ) were detected in the other 2 rivers (Hiwassee and Little River).

\section{DISCUSSION}

To evaluate the risk of disease posed by $B d$ infection to native amphibian populations, it is important to determine whether the infection strain is exotic or endemic. Causes of hellbender decline are mainly linked to habitat degradation or alteration, chemical contaminants, introduced species, commercial exploitation, diseases, and pathogens, such as $B d$ (Briggler et al. 2007b). Bd was first reported in Cryptobranchus alleganiensis bishopi from the North Fork of the White River, Ozark County, Missouri, USA (Briggler et al. 2007a), and is now geographically widespread in C. a. bishopi in the Ozark Highlands (Briggler et al. 2008). Our study has shown that chytrid strains found on both hellbender subspecies are not specific to cryptobranchids, but rather match common types distributed globally, supporting the exotic recent invasion hypothesis (Bodinof et al. 2011, Farrer et al. 2011).

All 3 haplotypes detected from hellbenders can be regarded as common types which have been detected from many different amphibian species and are genetically close to each other. Hapotype A differs from haplotype $\mathrm{E}$ at 1 indel region (continuous $10 \mathrm{bp}$ insertion or deletion), and haplotype E differs from haplotpye L at 1 indel region (continuous $6 \mathrm{bp}$ insertion or deletion; Fig. 1). However, these 3 haplotypes were distant (more than 10 substitutions, insertions, or deletions) from the specific haplotypes (B: AB435213, J: AB435220, and K: AB435221) observed on the Japanese giant salamander (Fig. 1 in this article; Fig. 6 in Goka et al. 2009; Fig. 2 in Bai et al. 2012). E (Bd04) AB435214 AGTCGAACAAA--ATTTATT TATTTTTTCGACAAATTAAT TGGAAATTGAATAATTT--- -------AATTGAAAATAAA TATTAAAAACAACTTTTGAC L (Bd11) AB435221 AGTCGAACAAA--ATTTATT TATTTTTTCGACAAATTAAT TGGAAATTGAATAATTTTAA TTT----AATTGAAAATAAA TATTAAAAACAACTTTTGAC B(Bd02) AB435212 AGTCGAACAAAAAATTTATT TATTTTTTCGACAAATTAAT TGGAAATGATTTAATTGAAA AAT----AATATTAAAAAAA TATTAAAA-CAACTTTTGAC J(Bd09) AB435219 AGTCGAACAAAAAATTTATT TATTTTTTCGACAAATTAAT TGGAAATGATTTAATTGAAG AAT----AATATTAAAAAA- TATTAAAA-CAACTTTTGAC K (Bd10) AB435220 AGTCGAACAAAAAATTTATT TATTTTTTCGACAAATTAAT TGGAAATGATTTAATTGAAA AAT----AATATTAAAAAA- TATTAAAA-CAACTTTTGAC

101

120

140

160

180

200

A(Bd01) AB435211 AACGGATCTCTTGGCTCTCG CAACGATGAAGAACGCAGCG AAATGCGATACGTAATGTGA ATTGCAAACCTTTGTGAATC ATTAAATCTTTGAACGCACA E (Bd04) AB435214 AACGGATCTCTTGGCTCTCG CAACGATGAAGAACGCAGCG AAATGCGATACGTAATGTGA ATTGCAAACCTTTGTGAATC ATTAAATCTTTGAACGCACA L (Bd11) AB435221 AACGGATCTCTTGGCTCTCG CAACGATGAAGAACGCAGCG AAATGCGATACGTAATGTGA ATTGCAAACCTTTGTGAATC ATTAAATCTTTGAACGCACA B (Bd02) AB435212 AACGGATCTCTTGGCTCTCG CAACGATGAAGAACGCAGCG AAATGCGATACGTAATGTGA ATTGCAAACCTTTGTGAATC ATTAAATCTTTGAACGCACA J(Bd09) AB435219 AACGGATCTCTTGGCTCTCG CAACGATGAAGAACGCAGCG AAATGCGATACGTAATGTGA ATTGCAAACCTTTGTGAATC ATTAAATCTTTGAACGCACA K(Bd10) AB435220 AACGGATCTCTTGGCTCTCG CAACGATGAAGAACGCAGCG AAATGCGATACGTAATGTGA ATTGCAAACCTTTGTGAATC ATTAAATCTTTGAACGCACA

201 220 240 A (Bd01) AB435211 TTGCACTCGTAAAAGAGTAT ACATGTTTGAGAATTATAAA AATACATTGTCCGAATTGA E (Bd04) AB435214 TTGCACTCGTAAAAGAGTAT ACATGTTTGAGAATTATAAA AATACATTGTCCGAATTGA L (Bd11) AB435221 TTGCACTCGTAAAAGATTAT ACATGTTTGAGAATTATAAA AATACATTGTCCGAATTGA B (Bd02) AB435212 TTGCACTCGTAA--GAGTAT ACATGTTTGAGAATTATAAA AATACATTGTCCGAATTGA J(Bd09) AB435219 TTGCACTCGTAA--GAGTAT ACATGTTTGAGAATTATAAA AATACATTGTCCGAATTGA $\mathrm{K}(\mathrm{Bd} 10)$ AB435220 TTGCACTCGTAA--GAGTAT ACATGTTTGAGAATTATAAA AATACATTGTCCGAATTGA
Fig. 1. Batrachochytrium dendrobatidis. Alignment sequences among haplotypes detected from hellbenders Cryptobranchus alleganiensis (A, E, and $L$ ) and Japanese giant salamanders Andrias japonicus (B, J, and K) 
Several studies have revealed higher genetic diversity of $B d$ and a lower prevalence, and no clinical signs of chytridiomycosis in wild Asian amphibians. These studies found that some Asian amphibians carry the unique $B d$ strains which are divergent from other global strains and are endemic to Asia (Goka et al. 2009, Bai et al. 2012). This suggests that several Asian amphibians have established a commensal relationship with their specific $B d$ strains (Goka et al. 2009, Farrer et al. 2011, Savage et al. 2011, Swei et al. 2011, Bai et al. 2012), indicating that at least several Asian $B d$ strains are endemic, consistent with the 'Chytrid out of Asia' hypothesis. To deduce the history of spread of this pathogen, we must carefully examine the evolutionary relationship between $B d$ haplotypes. However, because only a short single locus, which does not include enough phylogenetic information, has been used for genetic analyses in recent studies (Goka et al. 2009, Bai et al. 2012, this study), it is difficult to elucidate their genetic relationships in detail. To clarify their genetic relationship and estimate their origin, further genetic surveys using new genetic markers are required. Although our results cannot conclusively support the 'Chytrid out of Asia' hypothesis, they are nevertheless quite suggestive.

Hellbender declines have been widespread and almost certainly involve multiple anthropogenic factors, posing a challenge to effective conservation. The best studied declines have occurred in the Ozark region, and have been characterized by low recruitment, poor body condition, impaired wound healing, and secondary infections (Wheeler et al. 2003, Briggler et al. 2007b). These factors point to stressed individuals which likely exhibit much higher susceptibility to exotic diseases such as $B d$. We strongly recommend implementing long-term surveys of prevalence and virulence of $B d$ on hellbender populations throughout their range.

Acknowledgements. We thank L. Irwin, B. Sharpe, D. Sharpe, B. Posey, J. Miller, D. McKnight, and A. Burris for their assistance in collecting amphibian samples. We also thank T. Johnson, S. Okada, K. Tamukai, Y. Une, and the Japan Wildlife Research Center for kind advice. This study was supported by the Global Environmental Research Fund (F-081; led by K.G.) of the Ministry of the Environment, Japan.

\section{LITERATURE CITED}

Annis SL, Dastoor FP, Ziel H, Daszak P, Longcore JE (2004) A DNA-based assay identifies Batrachochytrium dendrobatidis in amphibians. J Wildl Dis 40:420-428

Aplin K, Kirkpatrick P (2000) Chytridiomycosis in southwest Australia: historical sampling documents the date of introduction, rates of spread and seasonal epidemiology, and sheds new light on chytrid ecology. In: Williams K, Speare R (eds) Getting the jump! on amphibian disease: conference and workshop compendium: 24. Rainforest CRC, Cairns, p 24

Bai C, Liu X, Fisher MC, Garner TWJ, Li Y (2012) Global and endemic Asian lineages of the emerging pathogenic fungus Batrachochytrium dendrobatidis widely infect amphibians in China. Divers Distrib 18:307-318

> Berger L, Speare R, Daszak P, Green DE and others (1998) Chytridiomycosis causes amphibian mortality associated with population declines in the rain forests of Australia and Central America. Proc Natl Acad Sci USA 95: 9031-9036

> Bodinof CM, Briggler JT, Duncan MC, Beringer J, Millspaugh JJ (2011) Historic occurrence of the amphibian chytrid fungus Batrachochytrium dendrobatidis in hellbender Cryptobranchus alleganiensis populations from Missouri. Dis Aquat Org 96:1-7

Bosch J, Martínez-Solano I, García-París M (2001) Evidence of a chytrid fungus infection involved in the decline of the common midwife toad (Alytes obstetricans) in protected areas of central Spain. Biol Conserv 97:331-337

Bradley GA, Rosen PC, Sredl MJ, Jones TR, Longcore JE (2002) Chytridiomycosis in native Arizona frogs. J Wildl Dis 38:206-212

Briggler JT, Ettiling J, Wanner M, Schuette C, Duncan M, Goellner K (2007a) Cryptobranchus alleganiensis (hellbender). Chytrid fungus. Herpetol Rev 38:174

Briggler JT, Utrup J, Davidson C, Humphries J and others (eds) (2007b) Hellbender population and habitat viability assessment: final report. IUCN/SSC Conservation Breeding Specialist Group, Apple Valley, MN

Briggler JT, Larson KA, Irwin KJ (2008) Presence of the amphibian chytrid fungus (Batrachochytrium dendrobatidis) on hellbenders (Cryptobranchus alleganiensis) in the Ozark Highlands. Herpetol Rev 39:443-444

> Farrer RA, Weinert LA, Bielby J, Garner TWJ and others (2011) Multiple emergences of genetically diverse amphibian-infecting chytrids include a globalized hypervirulent recombinant lineage. Proc Natl Acad Sci USA 108:18732-18736

- Fisher MC (2009) Endemic and introduced haplotypes of Batrachochytrium dendrobatidis in Japanese amphibians: sink or source? Mol Ecol 18:4731-4733

Goka K, Okabe K, Yoneda M, Niwa S (2001) Bumblebee commercialization will cause worldwide migration of parasitic mites. Mol Ecol 10:2095-2099

Goka K, Yokoyama J, Une Y, Kuroki T and others (2009) Amphibian chytridiomycosis in Japan: distribution, haplotypes, and possible route of entry into Japan. Mol Ecol 18:4757-4774

Gonynor JL, Yabsley MJ, Jensen JB (2011) A preliminary survey of Batrachochytrium dendrobatidis exposure in hellbenders from a stream in Georgia. Herpetol Rev 42: 58-59

Green DE, Dodd K (2007) Presence of amphibian chytrid fungus Batrachochytrium dendrobatidis and other amphibian pathogens at warm-water fish hatcheries in southeastern North America. Herpetol Conserv Biol 2: $43-47$

James TY, Litvintseva AP, Vilgalys R, Morgan JAT and others (2009) Rapid global expansion of the fungal disease chytridiomycosis into declining and healthy amphibian populations. PLoS Pathog 5:e1000458 
Kilpatrick AM, Briggs CJ, Daszak P (2010) The ecology and impact of chytridiomycosis: an emerging disease of amphibians. Trends Ecol Evol 25:109-118

Laurance WF, McDonald KR, Speare R (1996) Epidemic disease and the catastrophic decline of Australian rain forest frogs. Conserv Biol 10:406-413

Lips KR (1999) Mass mortality and population declines of anurans at an upland site in western Panama. Conserv Biol 13:117-125

Lips KR, Green DE, Papendick R (2003) Chytridiomycosis in wild frogs from southern Costa Rica. J Herpetol 37: 215-218

Lips KR, Brem F, Brenes R, Reeve JD and others (2006) Emerging infectious disease and the loss of biodiversity in a Neotropical amphibian community. Proc Natl Acad Sci USA 103:3165-3170

Lips KR, Diffendorfer J, Mendelson JR, Sears MW (2008) Riding the wave: reconciling the roles of disease and climate change in amphibian declines. PLoS Biol 6:e72

> Morehouse EA, James TY, Ganley AR, Vilgalys R, Berger L, Murphy PJ, Longcore JE (2003) Multilocus sequence typing suggests the chytrid pathogen of amphibians is a recently emerged clone. Mol Ecol 12:395-403

Morgan JA, Vredenburg VT, Rachowicz LJ, Knapp RA and others (2007) Population genetics of the frog-killing fungus Batrachochytrium dendrobatidis. Proc Natl Acad Sci USA 104:13845-13850

> Ouellet M, Mikaelian I, Pauli BD, Rodrigue J, Green DM (2005) Historical evidence for widespread chytrid infection in North American amphibian populations. Conserv Biol 19:1431-1440

Padgett-Flohr GE, Hopkins RL II (2009) Batrachochytrium dendrobatidis, a novel pathogen approaching endemism in central California. Dis Aquat Org 83:1-9

Pessier AP, Nichols DK, Longcore JE, Fuller MS (1999) Cutaneous chytridiomycosis in poison dart frogs (Dendrobates spp.) and White's tree frogs (Litoria caerulea). J Vet Diagn Invest 11:194-199

Pounds JA, Bustamante MR, Coloma LA, Consuegra JA and others (2006) Widespread amphibian extinctions from epidemic disease driven by global warming. Nature 439: $161-167$

Editorial responsibility: John Austin, Oldendorf/Luhe, Germany
Rachowicz LJ, Hero JM, Alford RA, Taylor JW and others (2005) The novel and endemic pathogen hypotheses: competing explanations for the origin of emerging infectious diseases of wildlife. Conserv Biol 19:1441-1448

> Ron SR, Duellman WE, Coloma LA, Bustamante MR (2003) Population decline of the Jambato toad Atelopus ignescens (Anura: Bufonidae) in the Andes of Ecuador. J Herpetol 37:116-126

> Savage AE, Grismer LL, Anuar S, Onn CK and others (2011) First record of Batrachochytrium dendrobatidis infecting four frog families from Peninsular Malaysia. EcoHealth 8: 121-128

Skerratt LF, Berger L, Speare R, Cashins S and others (2007) Spread of chytridiomycosis has caused the rapid global decline and extinction of frogs. EcoHealth 4:125-134

Souza MJ, Gray MJ, Colclough P, Miller DL (2012) Prevalence of infection by Batrachochytrium dendrobatidis and Ranavirus in eastern hellbenders (Cryptobranchus alleganiensis alleganiensis) in eastern Tennessee. J Wildl Dis 48:560-566

Storfer A, Alfaro M, Ridenhour B, Jancovich JK, Mech SG, Parris MJ, Collins JP (2007) Phylogenetic concordance analysis shows an emerging pathogen is novel and endemic. Ecol Lett 10:1075-1083

Swei A, Rowley JJL, Rödder D, Diesmos MLL and others (2011) Is chytridiomycosis an emerging infectious disease in Asia? PLoS ONE 6:e23179

Une Y, Kadekaru S, Tamukai K, Goka K, Kuroki T (2008) First report of spontaneous chytridiomycosis in frogs in Asia. Dis Aquat Org 82:157-160

Weldon C, du Preez LH, Hyatt AD, Muller R, Spears R (2004) Origin of the amphibian chytrid fungus. Emerg Infect Dis 10:2100-2105

Wheeler BA, Prosen R, Mathis A, Wilkinson RF (2003) Population declines of a long-lived salamander: a 20+ year study of hellbenders, Cryptobranchus alleganiensis. Biol Conserv 109:151-156

> Yang H, Baek H, Speare R, Webb R and others (2009) First detection of the amphibian chytrid fungus Batrachochytrium dendrobatidis in free-ranging populations of amphibians on mainland Asia: survey in South Korea. Dis Aquat Org 86:9-13

Submitted: July 16, 2012; Accepted: November 19, 2012 Proofs received from author(s): February 22, 2013 